SIMÕES, A.N.; MENEZES, J.B.; NUNES, G.H.S.; FREITAS, D.F.; GOMES JÚNIOR, J.; COSTA, F.B. MEDEIROS, P.H. Armazenamento refrigerado de híbridos de melão amarelo submetidos a diferentes épocas de colheita. Horticultura Brasileira, Brasília, v.23, n.1, p.112-116, jan.-mar. 2005.

\title{
Armazenamento refrigerado de híbridos de melão amarelo submetidos a diferentes épocas de colheita ${ }^{1}$
}

\author{
Adriano do N. Simões²; Josivan B. Menezes; Glauber H.S. Nunes; Diana F. de Freitas; Julio Gomes \\ Junior; Franciscleudo B. da Costa; Paulo H. de Medeiros \\ ESAM, NEP, C. Postal 137, 59625-900 Mossoró-RN; E-mail: simoesan@hotmail.com; ${ }^{2}$ Bolsista PIBIC/CNPq.
}

\section{RESUMO}

Avaliou-se a qualidade comercial de híbridos de melão amarelo cv. Gold Mine e Gold Pride, submetidos a diferentes épocas de colheita. Os frutos foram colhidos no pólo agrícola de Mossoró-Assu $(\mathrm{RN})$, e armazenados a $11 \pm 1^{\circ} \mathrm{C}$ e $90 \pm 5 \%$ UR, durante 28 dias. Utilizou-se o delineamento inteiramente casualizado em esquema fatorial 5 x 5 , com cinco repetições e um fruto por parcela. O primeiro fator constou das épocas de colheita ( 0 sem retardamento, 2; 4; 6 e 8 dias de retardamento da colheita) e o segundo, do tempo de armazenamento $(0 ; 7 ; 14 ; 21$ e 28 dias $)$. Avaliou-se a firmeza da polpa $(\mathrm{N})$, perda de massa $(\%)$, aparência externa e interna e conteúdo de sólidos solúveis totais (\%). A firmeza da polpa e a aparência interna foram fortemente influenciadas pelo retardamento da colheita, proporcionando frutos com colapso interno e menor resistência da polpa. O retardamento da colheita influenciou significativamente a perda de massa apenas para o híbrido Gold Mine, observando-se a partir do $21^{\circ}$ dia, maiores perdas de massa para os frutos colhidos com 4 e 6 dias de atraso na colheita. O retardamento no período de colheita induziu maior suscetibilidade a danos por frio em ambos os híbridos e aumento no teor de sólidos solúveis apenas para híbrido Gold Pride.

Palavras-chave: Cucumis melo inodorus Naud., conservação, injúria pelo frio, qualidade pós-colheita.

\begin{abstract}
Refrigerated storage of yellow melon at different harvest periods

The commercial quality of yellow melon 'Gold Mine' and 'Gold Pride' hybrids at different harvest times was examined. The fruits were harvested in the Mossoró-Assu agricultural pole, Rio Grande do Norte State, Brazil, being kept under $11 \pm 1^{\circ} \mathrm{C}$ and $90 \pm 5 \%$ relative humidity, during 28 days. A 5 x 5 factorial scheme in a completely randomized design was used with five replications and one fruit per plot. The first factor was recorded at harvest time $(0 ; 2 ; 4 ; 6$ and 8 days retardation of the harvest) and the second at the storage periods $(0 ; 7 ; 14 ; 21$ and 28 days). We evaluated the flesh firmness $(\mathrm{N})$, weight loss (\%), internal and external appearances and soluble solids content $(\%)$. The flesh firmness and the internal appearance were strongly influenced by the harvest delay, providing fruits with internal disorder and smaller flesh resistance. The harvest delay influenced significantly the weight loss of the Gold Mine hybrid with larger weight losses occurring after 21 days of storage in treatments where the harvest was delayed 4 and 6 days. The harvest delay induced larger susceptibility to chilling injury in both hybrids and increased the soluble solids content in the hybrid Gold Pride.
\end{abstract}

Keywords: Cucumis melo inodorus Naud., conservation, chilling injury, postharvest quality.

(Recebido para publicação em 6 de fevereiro de 2004 e aceito em 18 de novembro de 2004)

$\mathrm{O}$ melão (Cucumis melo L.) é uma das hortaliças mais importantes no mundo, com área cultivada em torno de 1,154 milhões de hectares e produção superior a 19,51 milhões de toneladas. A China é o principal produtor mundial, sendo responsável por $35 \%$ da produção global, seguida pela Turquia com $9,22 \%$, pelo Irã com $8,15 \%$ e pelos EUA com $6,46 \%$. O Brasil, com área de 15 mil hectares dedicada a esse cultivo, obteve produção de cerca de 145.000 toneladas (FAO, 2000).

A cultura do melão, dentre as que são exploradas no Nordeste brasileiro, tornou-se a de maior expressão social e econômica, absorvendo mais mão-de-obra e gerando um montante considerável de divisas para a economia nacional, com aproximadamente 42 mil empregos diretos, além dos indiretos (FAO, 2000).

A qualidade do melão tem sido relacionada a diferentes fatores como firmeza da polpa, conteúdo de sólidos solúveis (SS) e avaliações subjetivas relacionadas à aparência externa e interna (Menezes et al., 1998). Essas características estão altamente relacionadas com o estádio de maturação, que é um dos principais fatores determinantes da vida útil e da qualidade final dos frutos (Kader, 1994). Quando a colheita é feita antes que o fruto tenha completado o seu desenvolvimento, a translocação de assimilados é interrompida, resultando em produto com baixo teor de açúcares e pouca aceitação por parte dos consumidores. No entanto, essa técnica é utilizada com o objetivo de prolongar a vida útil pós-colheita, mesmo que os frutos não atinjam sua melhor qualidade comestível (Mutton et al., 1981).

Alguns importadores europeus manifestaram sua insatisfação com a qualidade do melão amarelo proveniente do Brasil no que diz respeito ao baixo conteúdo de sólidos solúveis ( 9 a 10\%) o que, apesar de atender às regulamentações do mercado, propicia preços insatisfatórios. Dentre as diversas opções tecnológicas para aumentar o conteúdo de açúcares no melão, está o retardamento da colheita, visando prolongar o tempo em que o fruto per-

${ }^{1}$ Parte da monografia de graduação em Agronomia do primeiro autor, apresentada à ESAM. 
manece ligado à planta após ter atingido a maturidade comercial (Mutton et al., 1981).

O objetivo deste trabalho foi avaliar a qualidade comercial dos híbridos de melão amarelo, Gold Mine e Gold Pride, durante o armazenamento refrigerado, quando submetido ao retardamento da colheita por até oito dias.

\section{MATERIAL E MÉTODOS}

Os frutos foram colhidos da fazenda São João localizada no município de Mossoró, com altitude de $94 \mathrm{~m}$; longitude de $5^{\circ} 04^{\prime} 48^{\prime \prime} \mathrm{S}$ e latitude de $37^{\circ} 37^{\prime} 00^{\prime \prime} \mathrm{W}$. O clima do local é semiárido, com temperatura média em torno de $27,4^{\circ} \mathrm{C}$ e umidade relativa média do ar de $70 \%$.

Foram avaliados híbridos de melão amarelo 'Gold Mine' e 'Gold Pride', colhidos aos 63 ; 65; 67; 69 e 71 dias e aos $61 ; 63 ; 65 ; 67$ e 69 dias após o semeio, respectivamente, e armazenados por $0 ; 7 ; 14 ; 21$ e 28 dias. O delineamento experimental utilizado para cada híbrido foi o inteiramente casualizado, em esquema fatorial $5 \times 5$, sendo as épocas de retardamento da colheita por 0 (sem retardamento), 2; 4; 6 e 8 dias o primeiro fator e, o segundo fator o período de armazenamento. Foram utilizadas cinco repetições de um fruto.

O semeio dos híbridos foi feito em dois locais da fazenda, com características físicas de solo semelhantes. O híbrido Gold Mine foi semeado em 01/ 06/2000 e o Gold Pride em 18/06/2000, ambos com espaçamento de 2,0 m entre fileiras e 0,3 m entre plantas, em área total de 1,66 ha.

As colheitas foram realizadas pela manhã. Os frutos foram selecionados e embalados na linha de embalagem feita em caixa tipo exportação. Utilizaramse apenas frutos do tipo 6 (seis frutos/ caixa), com massa variando de 1,74 a $1,91 \mathrm{~kg}$.

Imediatamente após a seleção, os melões foram transportados ao laboratório da ESAM, onde foram identificados, pesados, sorteados para a formação das parcelas experimentais (25 frutos) e armazenados em câmaras frias a $11 \pm 1^{\circ} \mathrm{C}$ e $90 \pm 5 \%$ UR, por cinco dias e a $30 \pm 2^{\circ} \mathrm{C}$ e $50 \pm 5 \%$ de UR por mais dois dias. Os frutos foram avaliados no início do armazenamento e aos 7; 14; 21 e 28 dias. Após as duas condições de armazenamento, os frutos foram analisados, quanto à: Firmeza da polpa dividiu-se o fruto longitudinalmente em duas partes e em cada uma delas foram feitas duas leituras na polpa, em locais opostos com um penetrômetro de marca Mc Cormick modelo FT 327, com valor máximo de leitura de $30 \mathrm{lb}$ e plunger de ponteira cilíndrica de $8 \mathrm{~mm}$ de diâmetro. As leituras foram obtidas em libras força (lbf) e transformadas para Newton $(\mathrm{N})$, pelo fator 4,45; Perda de massa - determinada pela diferença entre massa no tempo inicial e aquela obtida em cada época. Os resultados foram expressos em percentagem (\%); Aparência externa e interna foram avaliadas utilizando-se uma escala visual e subjetiva considerando a ausência ou presença de defeitos. Para a aparência externa considerou-se a presença de depressões, murcha, injúria por frio e/ou presença de fungos, utilizando-se a escala de 1 a 5 (1=frutos extremamente deteriorados e $5=$ ausência de defeitos nos frutos). Na avaliação da aparência interna, considerou-se a presença de colapso interno, sementes soltas e/ou líquido na cavidade, utilizando-se escala semelhante à da aparência externa. Foram considerados frutos inadequados para comercialização, aqueles cuja nota apresentaram valores iguais ou inferiores a 3,0 (para aparência interna) e 4,0 (para aparência externa); Conteúdo de sólidos solúveis totais (SST) - foi determinado em duplicata por refratometria, utilizando-se um refratômetro digital, modelo PR-100, Palette (Attago Co., LTD, Japão) com compensação automática de temperatura, conforme normas da AOAC (1992). Os resultados foram expressos em percentagem $(\%)$.

Os dados foram submetidos à análise de variância usando o software SISVAR - UFLA. Utilizaram-se para a escolha dos modelos de regressão mais adequados: $\mathrm{R}^{2}>70 \%$, significância das estimativas dos parâmetros dos modelos de regressão, significância dos desvios de regressão e análises gráficas dos resíduos. As análises de regressão das interações entre os fatores foram feitas no programa 'Table Curve'(Jandel Cientific, 1991).

\section{RESULTADOS E DISCUSSÃO}

A interação foi significativa entre as épocas de colheita e os tempos de armazenamento, para todas as características avaliadas, com exceção da perda de massa do híbrido Gold Pride e do conteúdo de sólidos solúveis do híbrido Gold Mine.

Os frutos dos dois híbridos colhidos com até quatro dias de retardamento (63 a 67 dias após a semeadura para o híbrido Gold Mine e 61 a 65 dias para o híbrido Gold Pride), mantiveram maior firmeza, ou seja, foram menos suscetíveis ao amolecimento da polpa no final do período de armazenamento (Figura 1A e 1B). Para o híbrido Gold Mine, os frutos colhidos aos 63 dias (sem retardamento) apresentaram redução de firmeza mais acentuada a partir de 21 dias de armazenamento (Figura 1A). A redução da firmeza pode ser devido à perda de turgor, que é uma das responsáveis pelo amolecimento (Tucker, 1993), acontecendo principalmente no final do período de armazenamento nos frutos que passaram mais tempo no campo, com seis e oito dias de retardamento da colheita (Figura 1A e 1B). Além disso, a água ajuda a manter a estabilidade estrutural da parede celular (Bartley e Kenn, 1982), sendo possível que a exposição dos frutos por maior tempo à temperatura mais elevada (temperatura de campo) possa ter contribuído para ação mais intensa das enzimas envolvidas no amadurecimento no final do armazenamento. Mota (2000), estudando o comportamento pós-colheita de melão 'Gold Mine', produzido em períodos chuvosos, observou que os frutos submetidos ao armazenamento refrigerado a $11 \pm 2^{\circ} \mathrm{C}$ e UR de $90 \pm 5 \%$, apresentaram firmeza média de $20,0 \mathrm{~N}$ aos 35 dias, enquanto aqueles submetidos à temperatura de armazenamento de $25 \pm 2^{\circ} \mathrm{C}$ e UR de $50 \pm 5 \%$, apresentaram valores médios de 13,0 N, no mesmo período, valores inferiores aos obtidos neste experimento, visto que, o excesso de água pode ter contribuído para a redução da firmeza. 


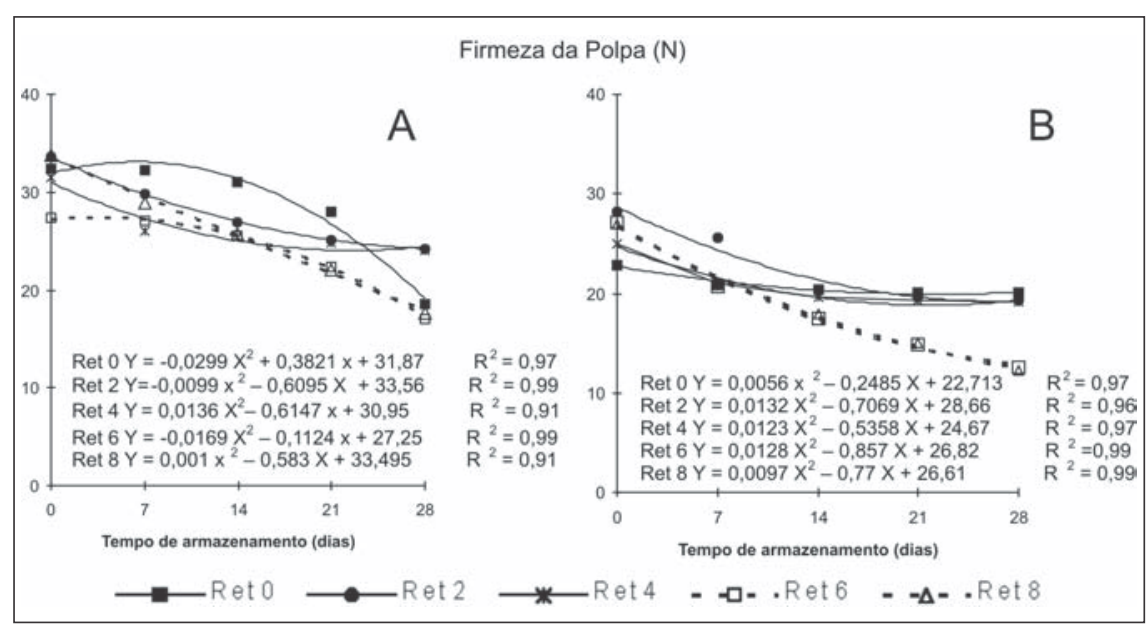

Figura 1. Firmeza da polpa de melões amarelos híbridos 'Gold Mine' (A) e 'Gold Pride' (B), colhidos com 63 e 61 dias (Ret 0 ) após o semeio, respectivamente, e submetidos ao retardamento na colheita por 2, 4, 6 e 8 dias. Armazenados em condições de $11 \pm 1^{\circ} \mathrm{C}$ e UR de $90 \pm 5 \%$. Mossoró, ESAM, 2001.

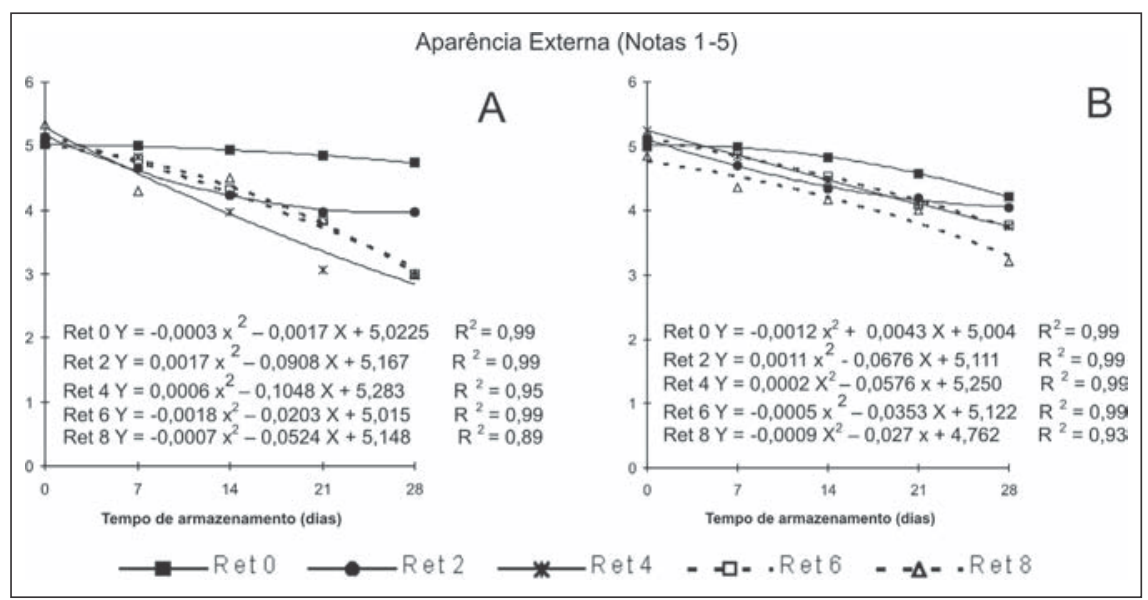

Figura 2. Aparência externa de melões amarelos híbridos 'Gold Mine' (A) e 'Gold Pride' (B), colhidos com 63 e 61 dias (Ret 0 ) após o semeio, respectivamente, e submetidos ao retardamento na colheita por 2, 4, 6 e 8 dias, armazenados em condições de $11 \pm 1^{\circ} \mathrm{C}$ e UR de $90 \pm 5 \%$. Mossoró, ESAM, 2001.

A partir do $21^{\circ}$ dia de armazenamento, a maior perda de massa dos frutos do híbrido Gold Mine ocorreu nos frutos em que se retardou-se a colheita por 6 e 4 dias, indicando que época de colheita pode influenciar na perda de massa, e portanto, na qualidade visual. Para o híbrido Gold Pride, a época de colheita não influenciou significativamente a perda de massa. Embora os resultados tenham dados contraditórios entre os híbridos, o importante foi que a perda de massa não foi suficiente para causar sintomas de murchamento, atingindo valores máximos próximos a $2,5 \%$ no final do período experimental para ambos os híbridos. Em melão ama-
$30 \pm 1^{\circ} \mathrm{C}$ e UR de $50 \pm 5 \%$. Mota (2000) observou no híbrido Gold Mine, armazenado em condições de $11 \pm 2^{\circ} \mathrm{C}$ e UR de $90 \pm 5 \%$, perda de massa de $2,33 \%$ com 35 dias e em condições de $25 \pm 2^{\circ} \mathrm{C}$ e UR de $50 \pm 5 \%$, no mesmo período, perda de $5,44 \%$.

A principal característica que conferiu a perda da qualidade externa dos frutos de ambos os híbridos foi a incidência de manchas amarronzadas, típicas de injúria por frio. Os frutos colhidos mais tardiamente foram mais suscetíveis ao dano a partir de sete dias de armazenamento (Figura 2A e 2B), enquanto os outros, apenas a partir de 14 dias (Figura 2A e 2B). Os frutos que não tiveram sua colheita retardada e os com dois dias de retardamento, foram os únicos que apresentaram notas superiores a 4,0 durante todo o armazenamento (Figura 2A e 2B).

De modo geral, o retardamento da colheita aumentou a suscetibilidade dos melões amarelos híbridos Gold Mine e Gold Pride a danos causados por frio, quando armazenados a $11 \pm 1^{\circ} \mathrm{C}$, provavelmente, em decorrência do maior período de tempo exposto à luz solar, pois no decorrer do ciclo, a parte vegetativa da planta, torna-se insuficiente para cobrir o fruto, tanto devido à senescência, como a fatores externos (danos físicos). Avaliando a qualidade pós-colheita do híbrido Gold Mine produzido em épocas chuvosas, Mota (2000) observou que os frutos submetidos à temperatura de armazenamento de $11 \pm 2^{\circ} \mathrm{C}$ e UR de $90 \pm 5 \%$, foram mais suscetíveis à incidência de manchas escuras na superfície da casca, sendo aparente a partir do $21^{\circ}$ dia de armazenamento. Gomes Júnior (2000) também verificou suscetibilidade a danos por frio em melões amarelos 'AF 646' armazenados durante 35 dias com UR de $90 \pm 5 \%$ a 10 e $12^{\circ} \mathrm{C}$, e em 'Rochedo' a $8 ; 10$ e $12^{\circ} \mathrm{C}$.

Os frutos do híbrido Gold Mine, colhidos com 63 dias e os do Gold Pride aos 61 dias, apresentaram boa qualidade interna até o final do armazenamento, obtendo notas superiores a três (Figura 3A e 3B). No entanto, todos os frutos que tiveram sua colheita retardada foram mais suscetíveis ao colapso interno, sintoma característico de perda de qualidade interna, principalmente a par- 
tir de 21 dias de armazenamento (Figura $3 \mathrm{~A}$ e $3 \mathrm{~B})$, como também foi observado por Mota (2000) para o híbrido Gold Mine, em que aos 35 dias tornaram-se inadequados ao consumo. Gomes Júnior (2000) observou que a cultivar de melão AF 646 teve sua qualidade interna prejudicada, principalmente em frutos armazenados a $12^{\circ} \mathrm{C}$, apresentando sintomas de colapso interno a partir dos 14 dias de armazenamento.

Os frutos de melão do híbrido Gold Pride que tiveram sua colheita retarda$\mathrm{da}$, apresentaram aumento nos teores de SST em quase todo o armazenamento, principalmente aqueles colhidos com 6 e 8 dias após o ponto de colheita (Figura 4) Entretanto, aumento dos teores de SST expressivos ficando próximos a 10\% (Figura 4). Os melões do híbrido Gold Mine, não apresentaram incremento dos SST com o retardamento da colheita. Embora os resultados tenham dados contraditórios entre os híbridos de melão amarelo, parece haver tendência de aumento de sólidos solúveis com o retardamento da colheita. No entanto, esse manejo deve ser feito com muito critério, pois outras características também importantes na qualidade do fruto poderão ser prejudicadas. Não observou variação significativa dos sólidos solúveis durante o armazenamento para os dois híbridos estudados, ou seja, constatou-se tendência de manutenção do conteúdo de sólidos solúveis ao longo do tempo de armazenamento (Figura 4), apesar da perda de massa ter aumentado no mesmo período. O mesmo foi observado por Menezes et al. (1995) e Carvalho et al. (1995) com melão amarelo.

Esses resultados sugerem que o retardamento de melão amarelo, pode aumentar o valor dos SST, como foi visto para o híbrido Gold Pride. No entanto, existe um limite máximo para esses melões permanecerem no campo. No presente experimento o limite máximo obtido foi de 2 dias. Pois foi observado que outros fatores reduziram a qualidade dos frutos quando armazenados, como a aparência externa, devido a injúria por frio, aparência interna, ao colapso interno, e firmeza da polpa, pelo amolecimento, influenciados sensivelmente pelo retardamento na colheita. Devendo-se levar em consideração para colheita, não ape-

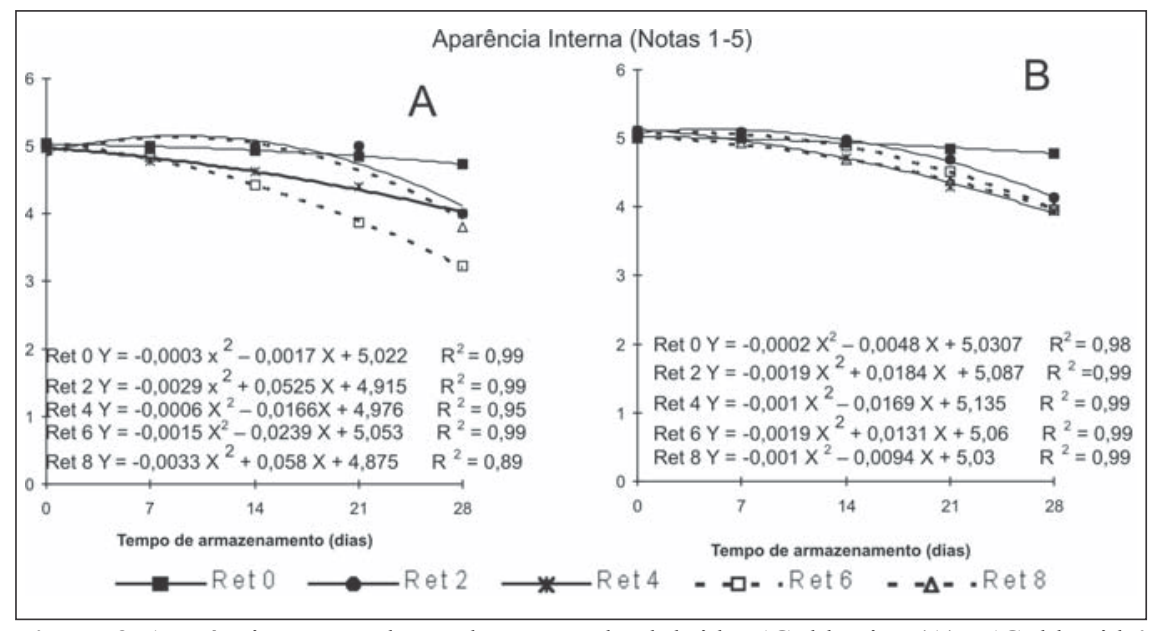

Figura 3. Aparência Interna dos melões amarelos híbridos 'Gold Mine (A) e 'Gold Pride' (B), colhidos com 63 e 61 dias (Ret 0 ) após o semeio, respectivamente, e submetidos ao retardamento na colheita por 2, 4, 6 e 8 dias, armazenados em condições de $11^{\circ} \pm 1^{\circ} \mathrm{C}$ e UR de $90 \pm 5 \%$. Mossoró, ESAM, 2001.

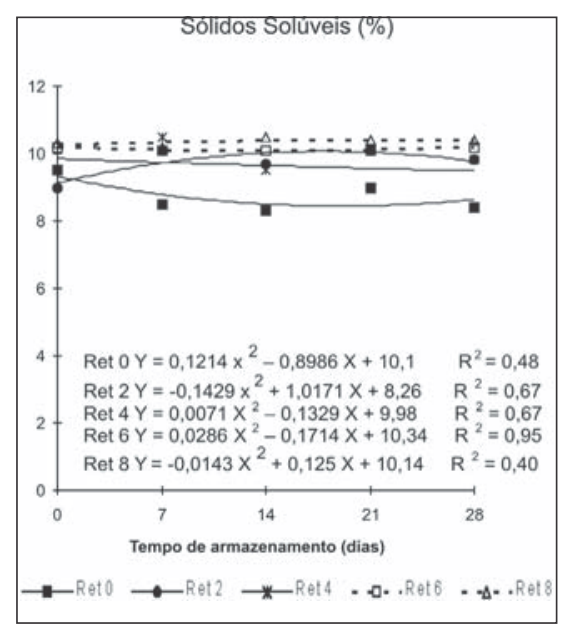

Figura 4. Conteúdo de sólidos solúveis de melões amarelos híbrido 'Gold Pride', colhidos com 61 dias (Ret 0) após o semeio, e submetidos ao retardamento na colheita por 2, 4, 6 e 8 dias, armazenados em condições de $11^{\circ} \pm 1^{\circ} \mathrm{C}$ e UR de $90 \pm 5 \%$. ESAM. Mossoró-RN, 2001.

nas o conteúdo de sólidos solúveis, mas também o destino do produto, ou seja, o espaço de tempo desde a colheita até o consumo. Nas condições de armazenamento do presente estudo, a qualidade comercial dos híbridos avaliados foi estimada de 28 dias, para os frutos que tiveram sua colheita retardada até 2 dias, e 14 dias para frutos submetidos ao retardamento de 4 a 6 dias. Não se recomenda o armazenamento nessas condições quando a colheita for retardada por mais de oito dias, devido principalmente aos sintomas de danos por frio.

\section{AGRADECIMENTOS}

Os autores agradecem à fazenda São João pela concessão dos frutos e ao CNPq, pela concessão da bolsa de iniciação científica.

\section{LITERATURA CITADA}

AOAC. (Washington, DC ) Official methods as analysis of the association of official analytical chemistry. 12 ed., 2 v. 1992.

BARTLEY, L.M.; KENN, M. The chemistry of textural changes in fruit during storage. Food Chemistry, v.9, n.7, p.47-58, 1982.

CARVALHO, H.A.; CHITARRA, M.I.F.; CHITARRA, A.B.; MENEZES, J.B. Vida útil póscolheita de melão 'Yellow King'. Revista Brasileira de Fruticultura, Cruz das Almas, v.17, n.3, p.111-118, 1995.

FAO. 2000. :Statistical Databases. Arquivo recuperado em junho de 2000.

GOMES JUNIOR, J. Suscetibilidade a danos pelo frio de melões amarelos AF 646 e Rochedo. Mossoró, 2000. 46 f. (Tese mestrado) - ESAM, Mossoró.

JANDEL SCIENTIFIC. User's manual. California: Jandel Scientific, 280 p. 1991.

KADER, A.A. Fruit maturity, ripening \& quality relationship. In: PAM, M. Perishables handling: Newsletter. Davis: University of California, p.2, 1994.

MENEZES, J.B. Bioquímica de maturação, amadurecimento e senescência de frutos e hortaliças. Mossoró. ESAM. 19 p. 1993. Apostila.

MENEZES, J.B.; CHITARRA, A.B.; CHITARRA, M.I.F.; CRVALHO, H.A. Caracterização pós-colheita do melão amarelo 'Agroflora 646'. Horticultura Brasileira, Brasília, v.13, n.2. p.150-153, 1995. 
MENEZES, J.B.; CHITARRA, M.I.F.; BICALHO. U.O. Caracterização do melão tipo gália durante a maturação. Horticultura Brasileira, Brasília, v.16, n.2, p.123-127, 1998.

MENEZES, J.B.; GOMES JÚNIOR, J.; ARAÚJO NETO, S.E.; SIMÕES, A.N. Armazenamento de dois genótipos de melão amarelo sob condições ambiente. Horticultura Brasileira, Brasília, v.19, n.1, p.24-49, 2001.
MOTA, J.K.M. Qualidade pós-colheita do melão 'Gold Mine' produzido na época das chuvas. Mossoró, 2000. 32 f. (Monografia graduação) ESAM, Mossoró.

MUTTON, L.L.; CURLLIS, B.R.; BLAKENEY, A.B. The objective definition of quality in rockmelon (Cucumis melo L.). Journal Science Food Agricultural, v.32, p.385-391. 1981.
TUCKER, G.A. Introdution. In: SEYMOUR, G.B.; TAYLOR, S.E.; TUCKER, G.A. Biochemistry of fruit ripening. London: Camman \& Hall, p.255-266, 1993.

ZUNIGA, F.J.P.; PEREZ, J.L.P.; ORTIZ, L.M.D Estudio de la fisiologia post-recolección y de la evolución de la calidad, durante la conservación frigorífica en atmósfera normal y controlada, de melon (Cucumis melo L.) cvs. 'Amarillo Oro' y 'Tendral Negro'. Alimentaria, Madrid, v.14, n.2, p.17-35, 1983. 